\title{
Ultrasonic Measurements and Metallurgical Properties of Ductile Cast Iron
}

\author{
M.A.Kenawy, A.M. Abdel-Fatah*, N.Okasha and M.EL-Gazary* \\ Physics Department, Faculty of Girls, Ain Shams Univ. Cairo, Egypt. \\ * Physics Department, National Institute for Standards, Geza, Egypt
}

\begin{abstract}
Ductile cast iron round bars was prepared using alloys with carbon equivalent percentage (C.E) in the range (4.50\% and $4.76 \%)$. Ultrasonic velocity and attenuation measured using pulse echo technique of frequencies 1 , 2 and $4 \mathrm{MHz}$.It found that ultrasonic velocity decreases with increasing size of casting module, while attenuation coefficient increases. In addition, the nodule count decreases with increasing the size of casting module, at the same time nodule size increases. An empirical formula relating the ultrasonic velocity and the mechanical properties namely ultimate strength, 0.2\%-offset yield, elongation and hardness) is suggested.
\end{abstract}




\section{Introduction:}

Ultrasonic pulse technique has been to be a practical method for evaluation of Castings qualitatively and quantitatively .By means of model and empirical relationships one can interpret certain changes in the structure of the material or the existence of inclusions and defects. The evaluation of the quality of a material depends upon the reliability of the concept regarding the interpretation of the signal [1].

Different ultrasonic methods are used to suit the type of measurement. These methods are characterized according to the measured quantity. Among these methods is the transit time (echo) method. It uses the signals, which are reflected from a discontinuity in the material. The probe can be used as an alternating transmitter and receiver. Several authors have used this technique for calculating the speed of ultrasonic waves for tempered and nontempered castings as well as attenuation in cast iron with different nodular ties $[2,3,4,5$, and 6].

In this work, we used the pulse echo technique for the measurement of ultrasonic shear and longitudinal velocities and attenuations of ductile cast iron with carbon equivalent and different casting modules at the frequencies 1,2 and $4 \mathrm{MHz}$.

\section{Experimental procedure:}

Procedure of ductile cast iron melts with $46 \%$ carbon equivalent preparation and casting are given else where $[1,7]$ specimens of the prepared cast iron were ground polished and chemically etched for microstructure examination and microphotography .

The number of nodules per unit area was determined by counting the number of nodules on the microphotographs taken under an optical microscope with $100 \mathrm{X}$ magnification and the nodularity percentage is given as:

$$
\text { Nodularity } \%=\frac{\text { Number of nodulus }}{\text { Total number of particles of graphite }} \times 100
$$

The matrix (volume fraction) of obtained phases (ferrite and pearlite) was measured using the point count technique on photomicrograph with magnification of $100 \mathrm{X}$.

Ultrasonic measurements (velocities and attenuation) were measured by pulse echo technique where an automatically adjusted short duration $(1 \sim 2-\mu \mathrm{sec})$ pulse of high amplitude is applied to a broad band transducer, which was driven at its center frequency. 
An appropriate specimen for the ultrasonic measurements was used in tensile test. A Shimadzu 50 tensile testing machine and Wolpert hardness test machine was used to determine the mechanical properties.

\section{Results and Discussion:}

Figures (1a,b,c and d) show the micrographs representing the structure of sections cut from specimens with different carbon equivalent (C.E) percentage and $0.75 \mathrm{~cm}$ casting module .It is clear from these photomicrographs that the nodularity increases as the carbon equivalent percentage increases.

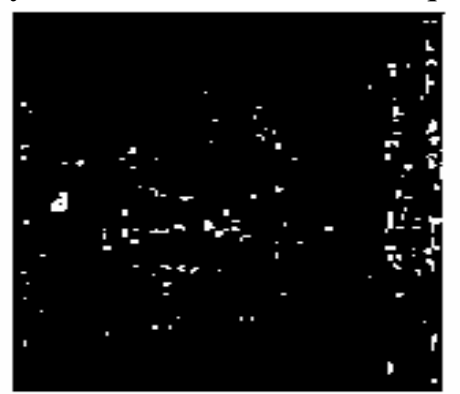

a) C.E. $4.76 \%, N=95 \%$

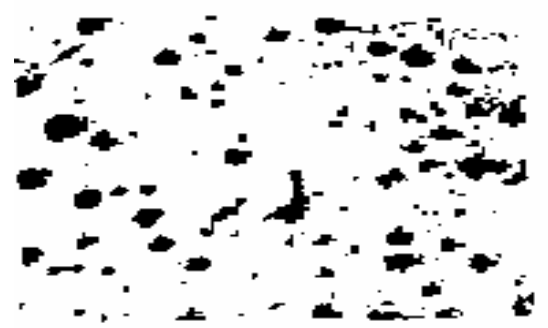

C) C.E. $4.4 .55 \%, N=85 \%$

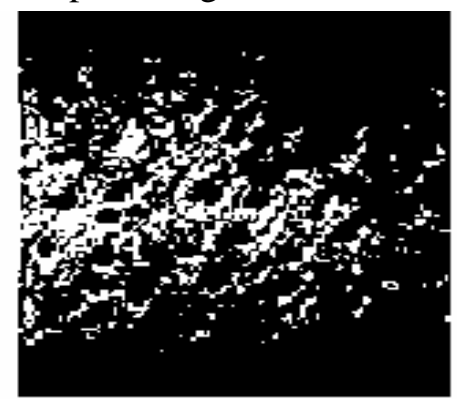

b) C.E. $4.60 \%, N=90 \%$

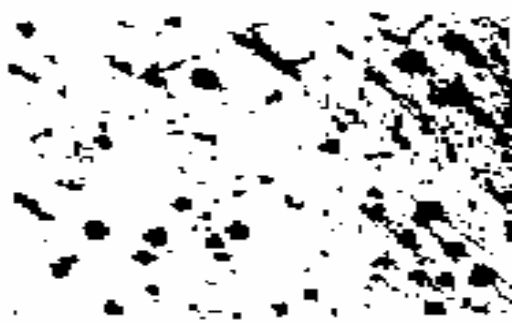

d) C.E. $4.50 \%, N=78 \%$

Fig.(1): Ultimate tensile stress and ductility as functions of degree of deformation for as drawn wires of Brasses with different $\mathrm{Zn}$ content.

The values of nodularity for different carbon equivalents are listed in Table (1) and plotted in Figure (2). The variation of nodularity with carbon equivalent is resulting from the increase of carbon content.

Table (1): Values of nodularity for different C.E\% and $0.75 \mathrm{~cm}$ casting module.

\begin{tabular}{|c|c|}
\hline Carbon equivalent $\%$ & Nodularity $\%$ \\
\hline 4.5 & 78 \\
\hline 4.55 & 85 \\
\hline 4.6 & 90 \\
\hline 4.76 & 95 \\
\hline
\end{tabular}


The microstructure examination of specimens of different casting modules (v/s) and $4.6 \%$ C.E, shows that the nodules count (n), consequently the nodule size are affected by the size of casting modules. It is clear from Fig. (3) that the nodule count decreases and the nodule size increases with increasing of casting size.

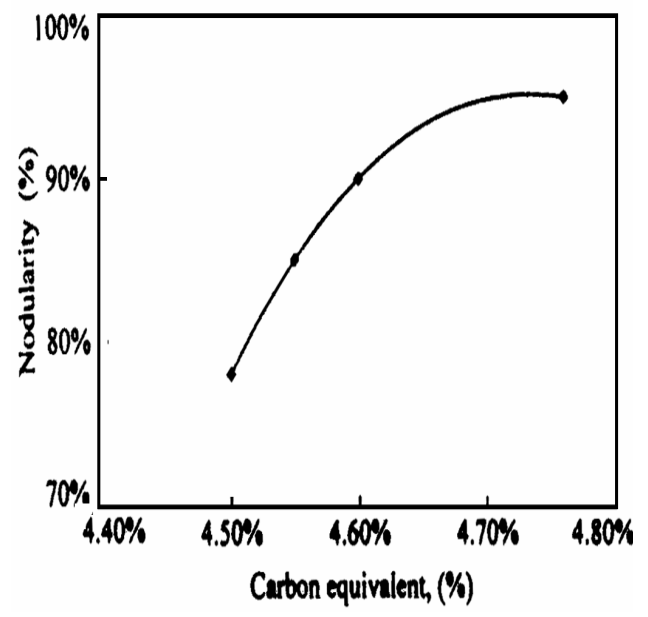

Fig. (2): Ultimate tensile stress and ductility as functions of degree of deformation for as drawn wires of Brasses with different $\mathrm{Zn}$ content. (After annealing at $\left.400^{\circ} \mathrm{C}\right)$.
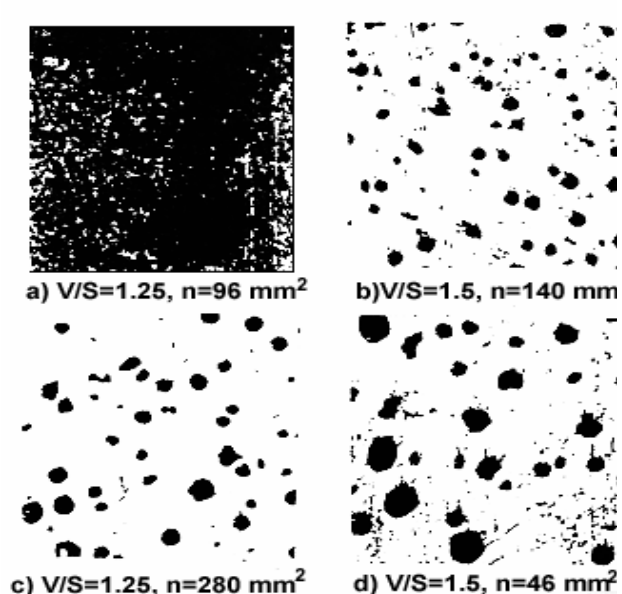

Fig. (3) : Ultimate tensile stress and ductility as functions of degree of deformation for as drawn wires of Brasses with different $\mathrm{Zn}$ content. (After annealing at $700^{\circ} \mathrm{C}$ ).

The graphic representation of the relation between nodule count and casting modules presented in Fig. (4). The decrease of nodule count with casting modules size explained by the rapidity of cooling that occurs for small casting modules. This means that smaller casting modules resulted in many nucleating centers for graphite nodules so that large graphite numbers with small sizes are created in small sections while, for large castings, because of slow rate of cooling, the number of nodules is less and there is a chance for nodules to grow [8].

Figures $(5,6)$ show the microstructures for the as-cast and annealed specimens for $0.75 \mathrm{~cm}$ casting module and $4.6 \% \mathrm{C}$. E. The matrix of the as-cast specimens is a pearlitic ferritic (from $60 \%$ to $65 \%$ pearlite) increasing slightly with the decrease of size of casting modules while the annealed matrix is mostly ferritic (95\%-100\%) increasing with the decrease of size of casting modules .The thinner is the casting module the rapid is the rate of cooling and consequently, the increase of pearlite percentage. 


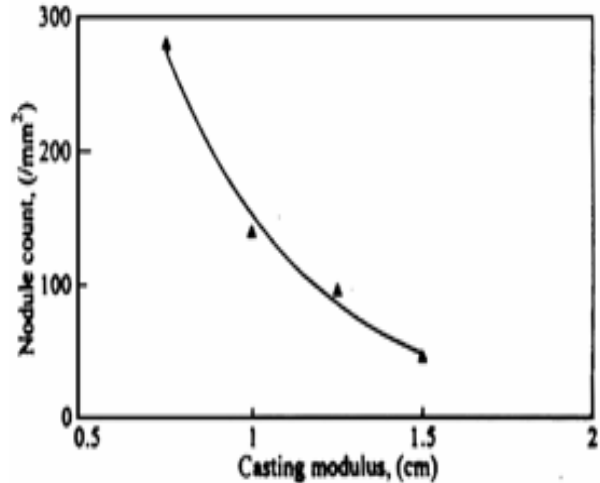

Fig. (4): The relation between U.T.S and $\mathrm{Zn}$ content for three different $<$ III $>$ texture degrees $\%$. $\mathrm{X}\langle\mathrm{III}\rangle=95 \%, \Delta<\mathrm{III}\rangle=83 \%$ and $\mathrm{O}<\mathrm{III}>=72 \%$

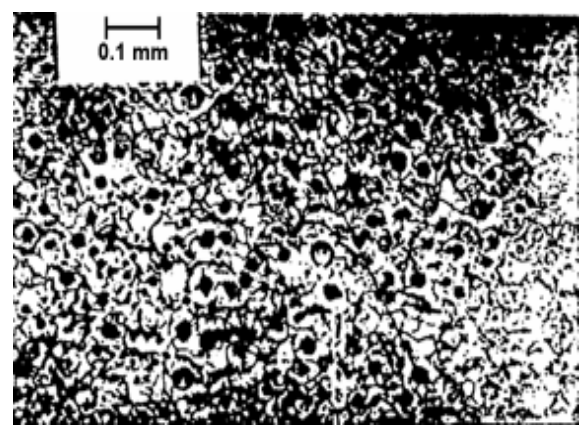

Fig. (6): The matrix of annealed specimen for 0.75 casting modulus, $2 \%$ natal etched at $100 \mathrm{X}$.

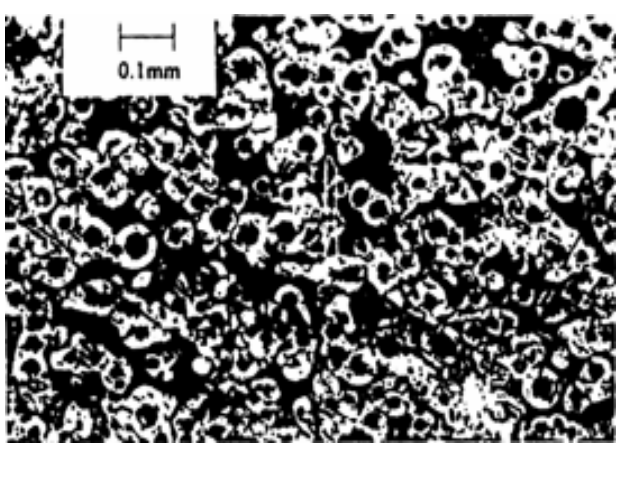

Fig. (5): The matrix of as-cast specimen for 0.75 casting modulus, $2 \%$ natal etched at $100 \mathrm{X}$.

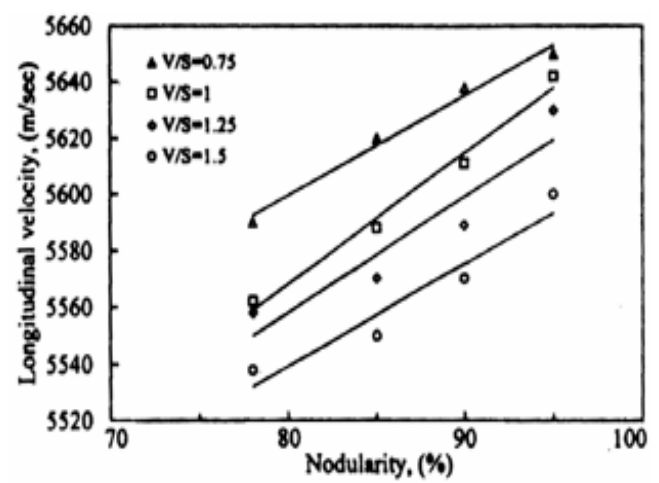

Fig. (7): Variation of longitudinal velocity with modularity for various casting modulus.

The relation between longitudinal ultrasonic velocity and nodularity percentage for specimens with different casting modules (at $4 \mathrm{MHz}$ ) represented in Fig. (7). It is clear from the figure that the value of ultrasonic velocity increases with increasing nodularity percentage, while it decreases with increasing size of casting modules and a linear relation could represent this as:

$$
\mathrm{V}=\mathrm{a}(\mathrm{N} \%)+\mathrm{b}
$$

where $a, b$ are constants depending on the type of material, their values for different casting modules are given in Table (2). 
Table (2): Constant for relation between ultrasonic longitudinal velocity and nodularity $\%$.

\begin{tabular}{|c|c|c|c|c|}
\hline $\mathrm{V} / \mathrm{S}(\mathrm{cm})$ & 0.75 & 1 & 1.25 & 1.5 \\
\hline $\mathrm{a}$ & 300 & 392.4 & 384.1 & 296.2 \\
\hline $\mathrm{b}$ & 5363.5 & 5259.4 & 5283.9 & 5306.8 \\
\hline
\end{tabular}

Figures $(8,9)$. Illustrate the relation between the nodule count and ultrasonic velocity (longitudinal and shear). The increase of ultrasonic velocity with nodularity and nodule count could be attributed to the continuity of the alloy as the nodularity and nodule count increase.

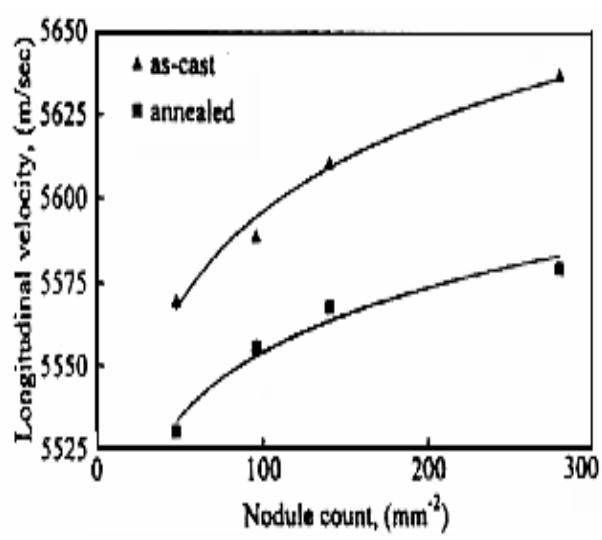

Fig.(8): Variation of longitudinal velocity with nodule count at $4 \mathrm{MHz}$ and $4.6 \% \mathrm{CE}$.

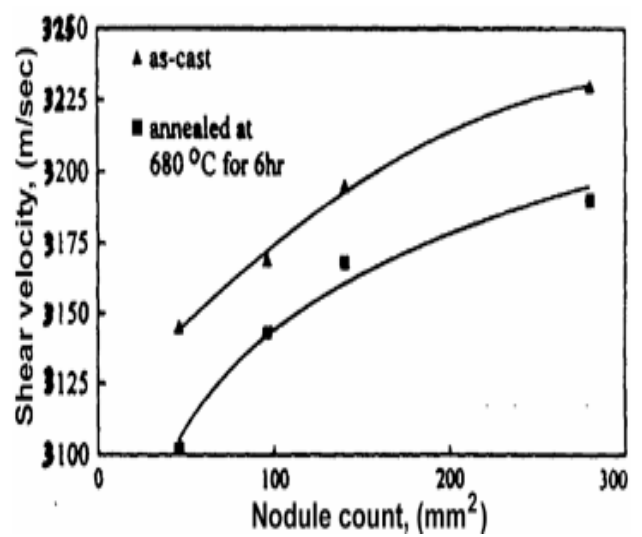

Fig. (9): Variation of shear velocity with nodule count at $4 \mathrm{MHz}$ and $4.6 \% \mathrm{CE}$.

The variation of ultrasonic attenuation coefficient with nodularity percentage for various casting modules at $4 \mathrm{MHz}$ frequency in Fig. (10). It is clear that the attenuation decreases with increasing nodularity percentage and increases with increasing size of casting module.

Figure (11) represents the variation of attenuation coefficient with the nodule count at different frequencies. It could be seen that as the nodule count increases the attenuation coefficient decreases and the value of attenuation coefficient of the annealed specimens are somewhat higher than the as cast. 


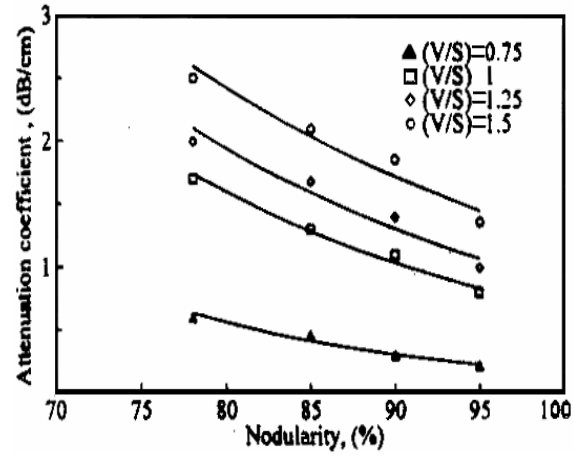

Fig. (10): Variation of attenuation coefficient with nodularity for various casting modularity for various casting modulus, at $4 \mathrm{MHz}$.

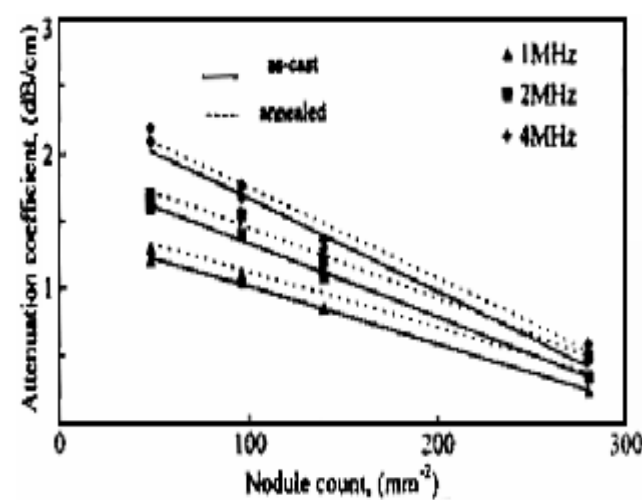

Fig. (11): Variation of attenuation coefficient with module count at 1,2 and $4 \mathrm{MHz} \% \mathrm{CE}$ specimens.

The decrease of attenuation with increasing the nodularity and nodule count is because nonnodular graphite reflects and scatters ultrasonic waves much more readily than nodular graphite. As the nodule, count increases the nodule size decreases and the scattering cross section of the nodules for the ultrasonic waves decreases; consequently, the attenuation increases.

A correlation between ultrasonic parameters and mechanical properties of cast iron could be deduced. Figures $(12,13)$ represent the relation between ultrasonic velocity and ultimate strength, $0.2 \%$ offset yield, elongation and hardness of the as cast and annealed specimens.

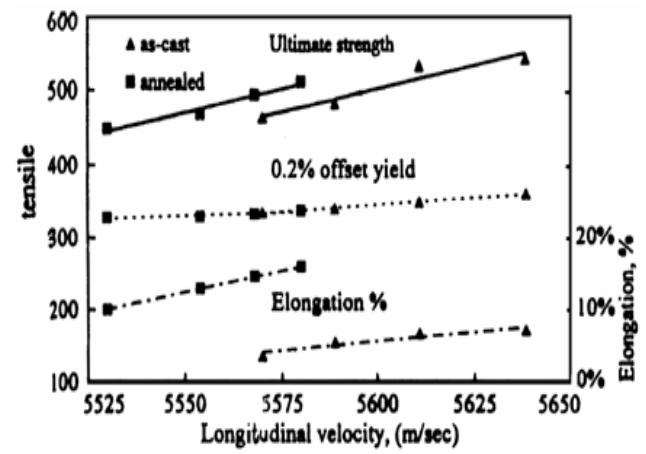

Fig. (12): Variation of longitudinal velocity with tensile properties.

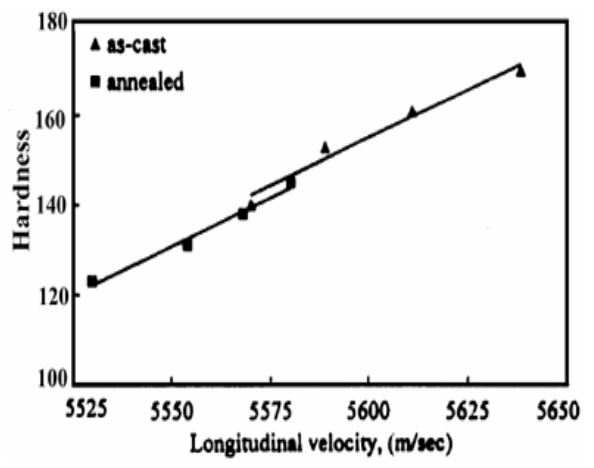

Fig. (13): Varition of hardness with longitudinal velocity

From these figures it is clear that irrespective of the material condition (as cast or annealed) the relation between the ultrasonic velocity and these mechanical parameters is linear. In general, the relation between mechanical properties and ultrasonic longitudinal velocity (vL) could be given by the empirical formula: 
Mechanical property $=\mathrm{a} v \mathrm{~L}-\mathrm{b}$

where $\mathrm{a}$ and $\mathrm{b}$ are constants depending of the type of mechanical property and the material and their values are listed in Table (3). This is in agreement with previous authors $[3,9,10$, and 11$]$.

Table (3): Constants for evaluation of mechanical properties using ultrasonic longitudinal velocity.

\begin{tabular}{|c|c|c|}
\hline Specimens & $\mathrm{a}$ & $\mathrm{b}$ \\
\hline \multirow{5}{*}{$\begin{array}{l}\text { U.T.S. }(\sigma u) \\
0.2 \% \text { offset yie } \\
\text { Hardness } \\
\text { Elongation\% }\end{array}$} & 0.9068 & 4566.7 \\
\hline & 0.3341 & 1525 \\
\hline & 0.462 & 2433.1 \\
\hline & 0.0012 & 6.5487 \\
\hline & 0.0005 & 2.8529 \\
\hline
\end{tabular}

\section{References:}

1. Krautkramer J.and Krautrkamer H.,: "Ultrasonic testing of materials" ,4th Ed.; Springer-Verlag, Berlin, (1990).

2. Milicev, S.; Iron and steel Foundry, 14, 95 (1984).

3. Lee, S. and Jia-Min G Suen, Metallu Trans; 20A 74 (1989).

4. Emerson P.J. and Simmons, W.; AFS Trans 9, 71 (1976).

5. Sergant, G.B. and Fuller, A.G., AFS Transactions, 11, 119 (1980).

6. Fuller, A.G., AFS Trans. 21, 391 (1980).

7. M. El-Gazery, M.Sc. Thesis, Ain Shams University, (1998).

8. Abdel-Kader, H. and Abdel-Fattah, A, J. Pure. Appl. Ultrasonic.,16, 60 (1994).

9. Patterson, B.R., AFS Tran. 98, 892 (1981).

10. Prasad, R. and Kumar, S., J. Pure Appl. Ultrasonic., 16, 51 (1994).

11. Voronokova, L., Sov. J. Nondestr. Test., 21, 82 (1985). 